\title{
A new catheter technique for His bundle recordings via the arm veins
}

\author{
Onkar S. Narula, Manfred Runge, and Philip Samet \\ From The Division of Cardiology, Department of Internal Medicine, Mount Sinai Medical Center of \\ Greater Miami, Miami Beach, Florida, and the University of Miami School of Medicine, \\ Miami, Florida, U.S.A.
}

A new technique for recording His bundle and right bundle-branch electrograms via the arm veins is described. In 25 patients an ordinary bipolar pacing catheter was introduced into an arm vein and the tip positioned in the right atrium. The catheter tip was looped in a figure-of-six (6) shape in the right atrium. The loop was advanced across the tricuspid valve into the right ventricle. A slight withdrawal of the catheter results in partial opening of the loop and approximation of the catheter tip to the vicinity of the His bundle. Further withdrawal of the catheter tip results in additional opening of the loop into a U shape with the tip directed towards the outflow tract of the right ventricle, enabling one to record right bundle-branch potentials. In 15 of the 25 patients simultaneous His bundle recordings were obtained by the above approach and via the conventional femoral route; the His bundle electrograms were similar in shape and duration. The conduction times, i.e. AH and HV, were also similar during normal sinus rhythm and atrial stimulation. The procedure time via the arm veins was comparable to or even shorter than the time required by the femoral approach.

The new catheter technique, $I$ ) provides an alternative route for catheter introduction in patients in whom femoral veins cannot be used, and 2) may prove to be the method of choice in selected cases requiring long-term monitoring of His bundle potentials in view of the stability of the His bundle recordings.

In the past 5 years His bundle recordings have made a significant contribution scientifically to the understanding of human electrophysiology and clinically to patient management (Narula et al., 1971 ; Narula and Samet, 197I ; Narula, 1973a, b; Rosen et al., 1970; Castellanos et al., 1970). This has been possible because of the ease with which His bundle potentials can be obtained with an electrode catheter. His bundle electrograms had been obtained in isolated cases, via an electrode catheter, as far back as 1960 (Giraud et al., 1960; Watson, Emslie-Smith, and Lowe, 1967). However, it was not until I968 that a femoral vein catheter technique for consistent His bundle recordings in man was independently and almost simultaneously developed in two separate laboratories (Scherlag et al., 1969; Narula et al., 1968). With this latter technique, an electrode catheter is introduced percutaneously through a femoral vein and is positioned against the septal leaflet of the tricuspid valve. Since the femoral route may not be feasible in all cases, an alternative approach via the arm veins has been independently

Received 30 May 1973. reported by two separate groups (Gallagher et al., 1973; Narula and Samet, 1972) Gallagher et al. have used a specially designed electrode catheter with a tip deflection device. However, we have been successful in obtaining His bundle recordings via the arm veins, with an ordinary bipolar pacing catheter (Narula and Samet, 1972).

The purpose of this study is to illustrate and describe in detail our technique for His bundle recordings via the arm veins with an ordinary bipolar pacing catheter, to discuss the advantages of this method as opposed to that requiring a special catheter (Gallagher et al., 1973), and to analyse the relative merits of this approach over that of the femoral route.

\section{Subjects and methods}

Twenty-five adult patients with atrioventricular conduction disturbances were studied in the postabsorptive state. Patients were premedicated with $100 \mathrm{mg}$ pentobarbitone sodium administered intramuscularly one hour before the study. His bundle recordings were obtained via an ordinary bipolar pacing catheter $(5 \mathrm{~F}$ in size and 
with ring electrodes $\mathrm{I} \mathrm{cm}$ apart) introduced percutaneously through a femoral vein, as described previously (Narula et al., 1970a). Another ordinary bipolar pacing catheter, without any preformed shape and similar to the femoral catheter, was introduced into the right atrium through an arm vein (cephalic or basilic). The catheter was introduced either percutaneously through a I4 gauge Medicut needle or through a surgically exposed vein in the right (23 patients) or left arm (2 patients). The catheter tip is looped into a figure-of-six in the right atrium (Fig. I). This loop is gradually advanced across the tricuspid valve into the right ventricle until the catheter tip is positioned in the region of the tricuspid valve (Fig. 2, Panel A). Slight withdrawal of the catheter at this time permits partial opening of the loop and placement of the recording tip electrodes in the vicinity of the His bundle. The proximity of both the catheter tips, i.e. the arm and femoral, is shown in Fig. 2, Panel B. The main aim is to position the electrodes in the superior angle of the tricuspid valve. This goal may be achieved by forming any shape of loop at the catheter tip. Fig. 3 shows that despite different shapes of the loop the recording electrodes are positioned in the same region, i.e. the His bundle. It is to be pointed out that in the patient shown in Fig. 3 the catheters were introduced from the left arm.

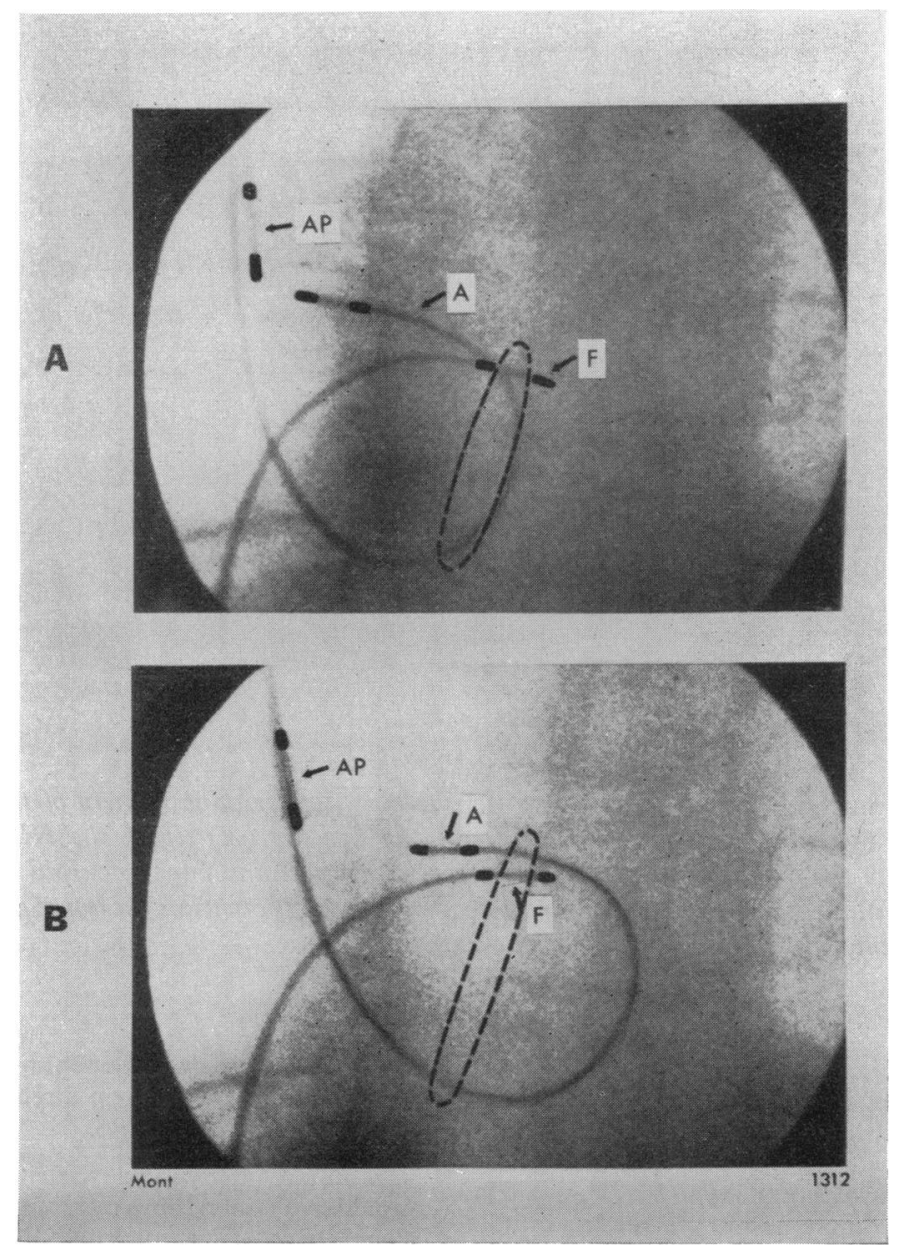

FIG. I Anteroposterior view of catheter positions during His bundle recordings. A) The catheter $(A)$ introduced through an arm vein is looped into a figure-of-six shape in the right atrium. The other catheter $(F)$ introduced via a femoral vein is sited in the His bundle region. $A$ third catheter $(A P)$ is for right atrial stimulation purposes. The dotted line denotes the position of the tricuspid valve. B) The sequence during advancement of the looped catheter $(A)$ towards the tricuspid valve and the right ventricle. 


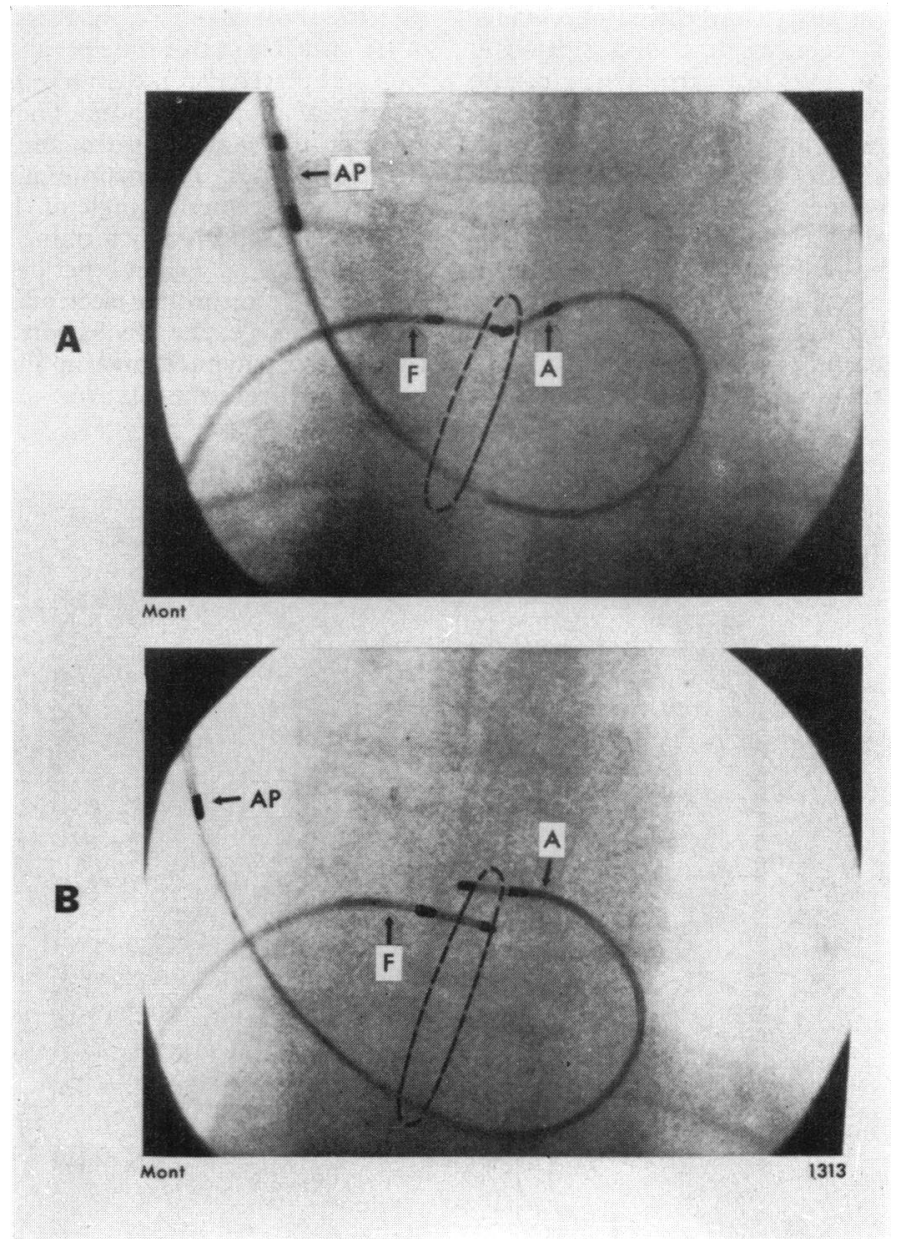

FIG. 2 The next sequence of catheter positions during further advancement of the loop into the right ventricle (panel $A$ ) and finally location of the catheter $(A)$ tip in the His bundle region (panel B). Note the catheter tip position in the superior portion of the tricuspid valve (outlined by the dotted line). In the latter position similar His bundle potentials were recorded from both the arm and femoral catheters (same patient as in Fig. I).

The proximal terminals of the bipolar electrode catheters were connected to a multichannel oscilloscopic photographic recorder. Simultaneous bipolar His bundle recordings were obtained from both catheters together with 3 standard electrocardiograph leads $(I, a V F, V I)$. The standard lead electrocardiograms and bipolar His bundle electrograms were recorded at $0-20$ and $40-200 \mathrm{~Hz}$, respectively. All recordings were made at paper speeds of $100 \mathrm{~mm} / \mathrm{sec}$ with time lines at one-second intervals. In I5 patients His bundle recordings were obtained via both routes, i.e. femoral and arm, and in the remaining Io via the arm veins alone. Right bundle-branch electrograms were also obtained via the arm catheter. This was achieved by an additional slight withdrawal of the catheter which enables opening of the loop into a $U$ shape with the catheter tip directed towards the outflow tract of the right ventricle.

In all patients studied, the right atrium was paced at progressively increasing rates up to 150 a minute or until Wenckebach cycles developed. Premature atrial beats were induced at varying coupling (PP) intervals. The above interventions in addition to the His bundle pacing and simultaneous $\mathrm{His}$ bundle recordings from the femoral catheter were used to validate the His bundle potential.

All patients were advised of the procedure, and informed consent was obtained. 


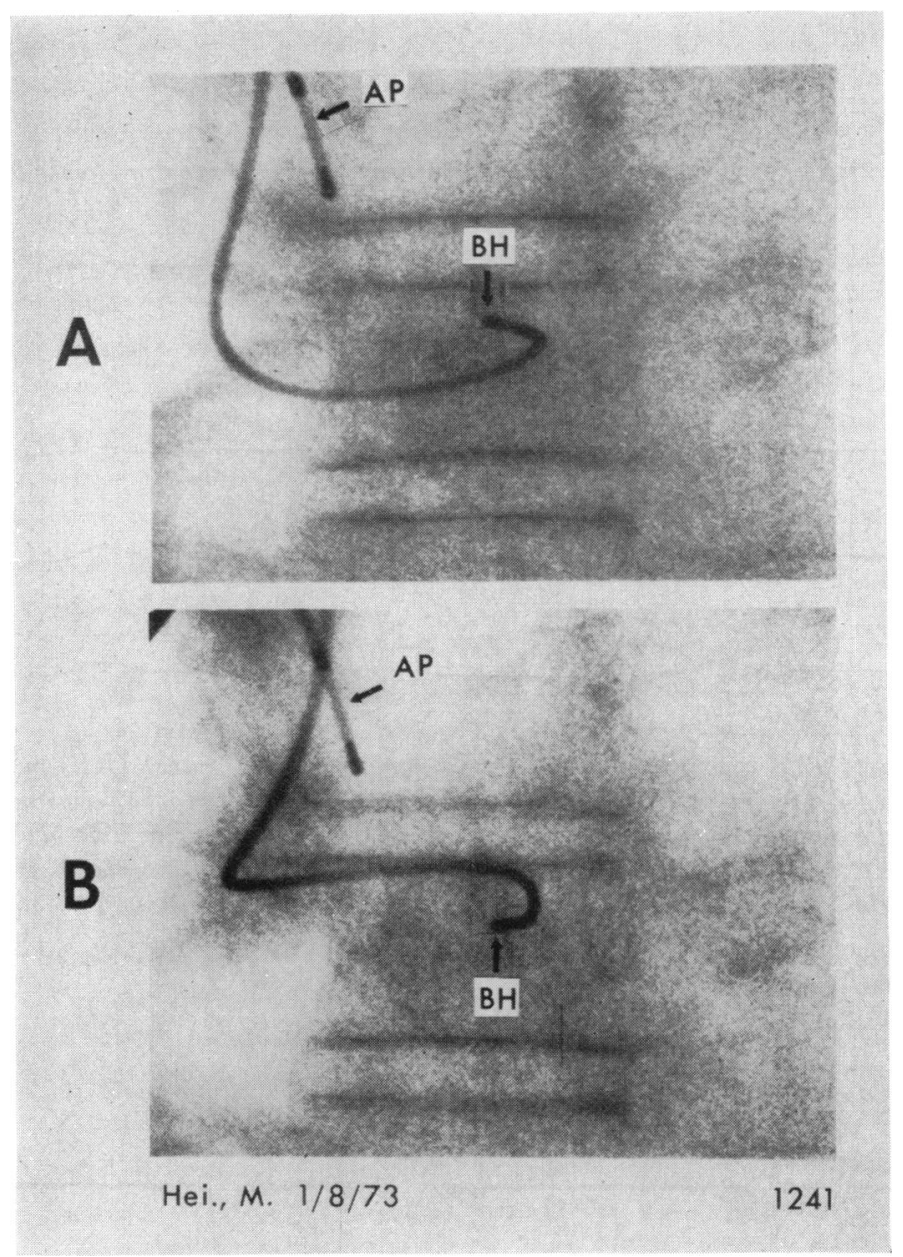

FIG. 3 Anteroposterior view shows that despite different shapes of catheter loops (panels $A$ and $B$ ) the recording electrodes are positioned in the same region, i.e. the His bundle. Identical His bundle electrograms were obtained in this patient by both the catheter loops. The His bundle recording catheter in this case was introduced via a left arm vein.

\section{Results}

His bundle electrograms were successfully obtained in all cases via the femoral route and in all except one via the arm route within five minutes of the catheter introduction into the right atrium. The procedure time via the arm was either comparable to or shorter than the femoral approach.

The recorded right bundle and His bundle potentials via both the arm and femoral approaches were similar in duration and shape, and conduction times, i.e. $A H, H V$, and $R B V$, were identical (Fig. 4 and 5). However, the amplitude of the His bundle deflection varied with the proximity of the recording electrodes to the His bundle and changed with a slight displacement in electrode position. The location of the His bundle deflection and the $\mathrm{HV}$ times were similar and constant throughout. On the other hand, the AH times, though usually similar on both the electrograms, may vary slightly at times (by 5 to $10 \mathrm{msec}$ ) depending upon the amplitude of the A wave (recorded from the area of the AV junction) and the catheter positions. The latter variations were not secondary to a change in His bundle deflection. The response to various interventions, e.g. induced premature atrial beats or atrial pacing was similar using both techniques (Fig. 5 and 6). The $\mathrm{AH}$ and $\mathrm{HV}$ times responded in identical fashions. During cardiac contraction, the arm 


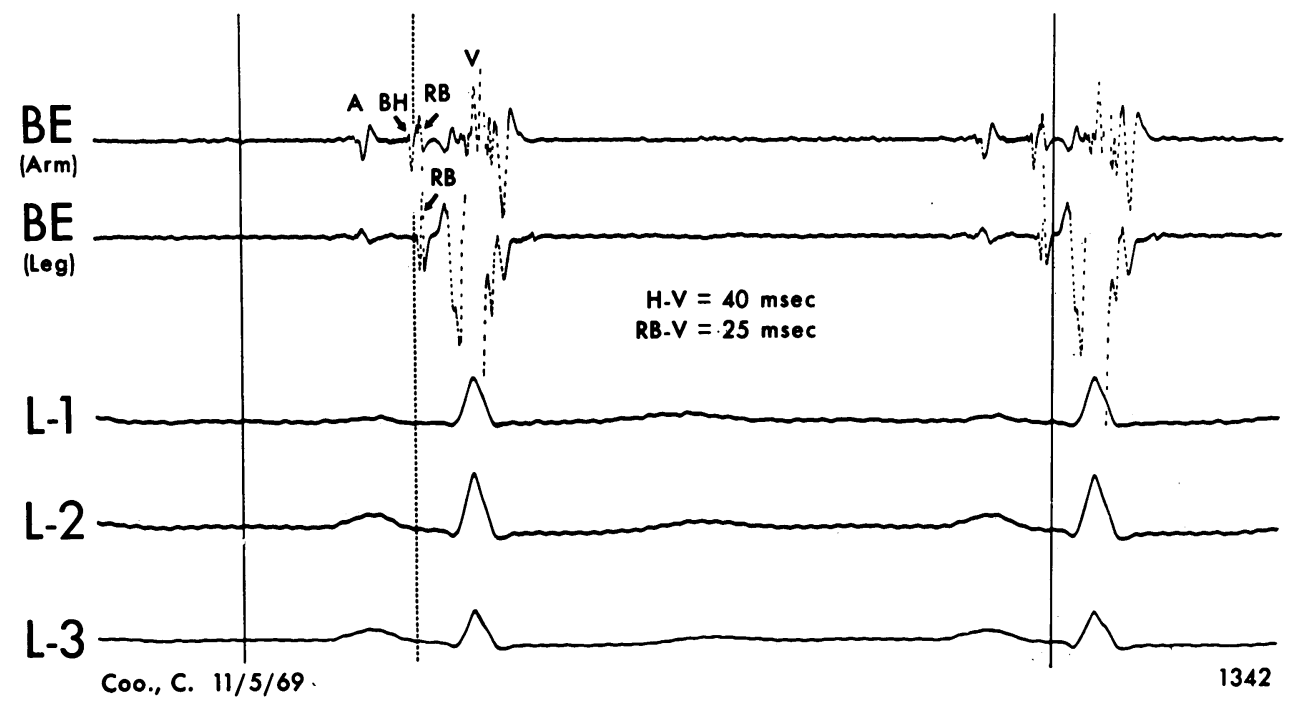

FIG. 4 Simultaneous bipolar recordings $(B E)$ of right bundle-branch $(R B)$ potentials via the arm and the leg catheters show similar $R B$ potentials. In addition, the recordings via the arm show His bundle deflection immediately preceding the RB electrogram. The HV (40 msec) and $R B V(25 \mathrm{msec}$ ) time intervals are within the normal range. $B H=$ bundle of His electrogram. Time lines on this and subsequent Figures are I sec apart.

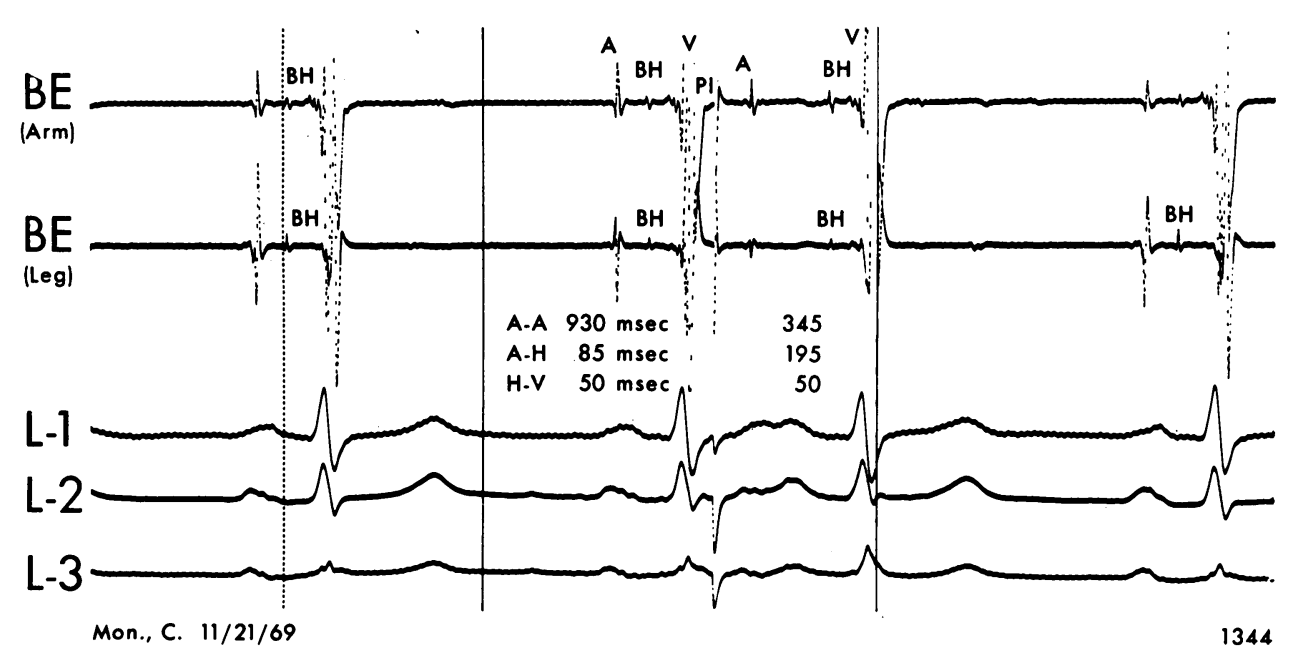

FIG. 5 Shows simultaneous bipolar His bundle recordings $(B E)$ via both the arm and leg catheters during normal sinus rhythm and an induced ( $P I=$ pacing impulse) premature atrial beat. During normal sinus rhythm the $A H(85 \mathrm{msec})$ and $H V(50 \mathrm{msec})$ times were identical on both the recordings. Similar His bundle potentials are seen during the premature atrial beat $(A-A=$ $345 \mathrm{msec})$, again with identical $A H(195 \mathrm{msec})$ and $H V$ (50 msec) times. Note the His bundle deflection recorded via the leg catheter varies slightly in amplitude whereas that from the arm remains essentially unchanged, suggesting the stability of recordings via the arm route. 


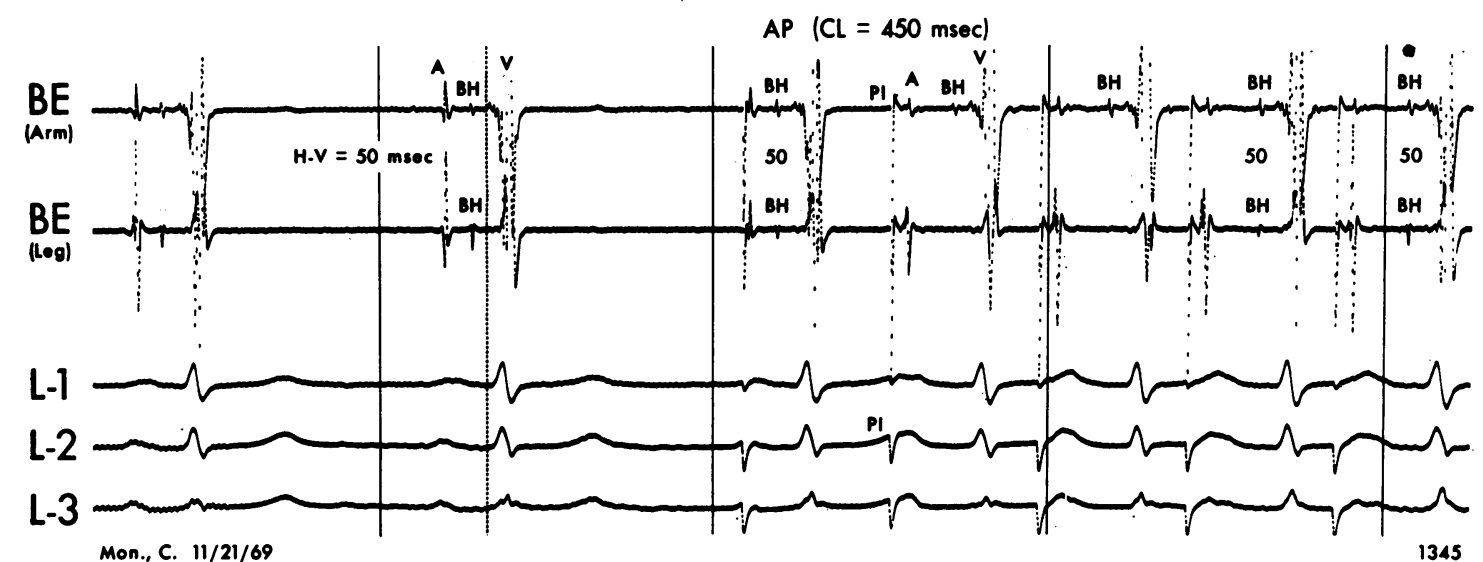

Mon., C. $11 / 21 / 69$

FIG. 6 Simultaneous His bundle recordings (BE) via both the arm and femoral routes during normal sinus rhythm and atrial pacing $(A P)$. (The same patient as in Fig. 5.) The His bundle potentials and the $H V$ time ( $50 \mathrm{msec}$ ) remain similar on both the $B E$ recordings. Note the disappearance (4th and 5th) and return (last two beats) of His bundle potentials on the recording via the leg catheter, whereas the His bundle potentials via the arm catheter remained stable and constant. $C L=$ cycle length.

catheter tip moves little because of the loop formation and thus enables stable His bundle recordings; whereas the femoral catheter shows a greater degree of to and fro movement across the tricuspid valve (Fig. 2, 5, and 6). Though His bundle stimulation was successful via the femoral route, it could not be achieved in all cases via the arm approach.

No complications were observed by the arm technique. The presence of a catheter loop in the right atrium or right ventricle during His bundle recordings did not result in any ventricular arrhythmias.

\section{Discussion}

A brief abstract of this new technique has been reported previously by us (Narula and Samet, I972). The present study illustrates the technique in detail along with our additional experience. The arm approach provides a new alternative method of recording His bundle and right bundle electrograms. Our method is different from another recently reported (Gallagher et al., I973). In contrast to the specially designed tripolar $(6 \mathrm{~F})$ electrode catheter with a tip deflection device used by Gallagher and associates, we have used an ordinary bipolar pacing $(5 \mathrm{~F})$ catheter for His bundle recordings via the arm veins (Narula and Samet, 1972). Our approach offers the following advantages. a) It eliminates the necessity for acquiring additional specially designed catheters at extra cost, especially for laboratories with a limited budget. b) It pro- vides an opportunity to obtain His bundle electrograms in a majority of the hospitals with standard fluoroscopic equipment and an ordinary pacing catheter available. c) The smaller size of the catheter ( $5 \mathrm{~F}$ as compared to $6 \mathrm{~F}$ ) enables percutaneous insertion of the catheter in an arm vein through the readily available I4 gauge Medicut needle. Furthermore, because of the flexibility of the ordinary pacing catheters resulting from their smaller size $(5 \mathrm{~F})$ and smaller number of electrodes (two), the catheter can easily be manoeuvred through the shoulder region while using the cephalic vein. The latter veins are usually larger in size than the superficial basilic veins, and in our experience we have successfully used the superficial cephalic veins in at least 80 per cent of the cases attempted; the latter veins were entered percutaneously in almost all of the cases. In addition, either of the arms, right or left, may be used. d) Since some of the patients studied may be candidates for a temporary pacemaker, the same catheter can be readily left in place (atrium or ventricle) for pacing purposes without requiring a change in catheter. e) It eliminates the need to shave the groins and pubic hair.

It is of interest to note that, though the very first His bundle electrograms in man were obtained via an electrode catheter introduced through an arm vein, the initial workers were successful in only a few cases (Giraud et al., 1960; Watson et al., 1967). On the other hand, subsequently the use of the femoral route for catheter introduction has consistently enabled His bundle recordings to be 
-

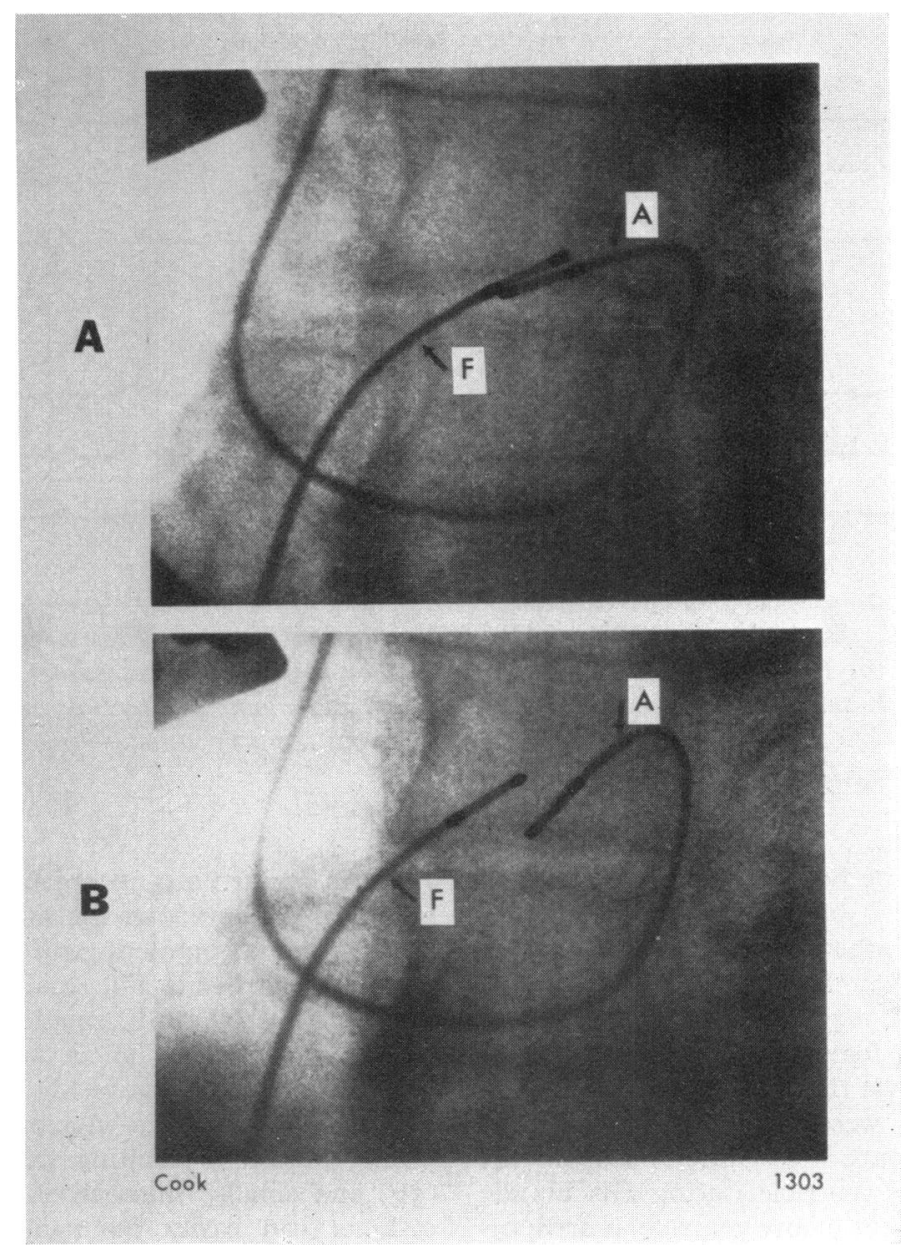

FIG. 7 Position of two separate recording catheters (with electrodes $I \mathrm{~cm}$ apart) from which similar His bundle potentials with identical HV times were obtained despite a significant distance between the two pairs. This suggests, a) that pinpoint catheter placement is not necessary for His bundle recordings; $b$ ) that the His bundle deflection does not represent recordings from only a localized portion of the His bundle adjacent to the catheter tip.

obtained (Narula et al., 1968, 1970a, I971; Narula and Samet, 197I; Narula, 1973a, b; Rosen et al., 1970; Castellanos et al., 1970; Scherlag et al., 1969). The reasons for failure of the initial attempts through the arm veins are explained by the anatomy of the AV conducting tissue. The His bundle is located in the superior portion or angle of the tricuspid valve and along its septal leaflet. Thus, an electrode catheter inserted from the leg is automatically directed to the superior angle of the tricuspid valve or the His bundle region (Fig. 2), whereas a catheter from the arm is headed in the opposite direction to the inferior portion or angle of the tricuspid valve. The recent efforts in the development of the arm technique have therefore been directed at devising a method by which the catheter tip may be placed in the superior angle of the tricuspid valve. Gallagher and associates (1973) have overcome this difficulty by the use of a tip deflection device to position the catheter tip in the desired direction. On the other hand, we have accomplished this more simply by using an ordinary bipolar pacing catheter to form a figure-of-six loop within the right atrium and advancing the looped tip in the desired region (Fig. 6). Our technique is simple and persons skilled in right heart 
catheterization should be able readily to perform this.

We have also observed that similar His bundle electrograms can be recorded via two separate catheters with tips relatively far apart from each other. One such example is shown in Fig. 7. Despite a significant movement in the position of the two catheters ( $A$ and $F$ ) during different phases of cardiac cycle, identical His bundle electrograms were obtained. This suggests that a) pin-point localization of the catheter electrodes is not necessary for His bundle recordings; b) the His bundle electrogram represents the activity of the entire His bundle rather than a portion of it or of the fibres adjacent to the recording electrodes (Rosen et al., 1971 ; James, 1970). If the latter were the case, then the His bundle electrograms obtained by two catheters relatively far apart (Fig. 7) should have different duration of His bundle deflections and HV times, but this was not so.

On the other hand, the electrode catheter tip must be precisely directed and positioned selectively to stimulate the His bundle. His bundle stimulation via the femoral approach has been successful in several hundred cases in our hands (Narula, Scherlag, and Samet, 1970b; Narula, 1973c). The reasons for the lack of success by others is probably due to their use of multipolar electrode catheters (especially Elecath catheters) which are not flexible to the same degree as a smaller catheter with only two electrodes. In our hands 'dacron' woven ordinary bipolar pacing catheters $(5 F)$ have proved ideal for recordings and stimulation of the His bundle. However, it has been observed that despite excellent recordings of His bundle potentials, stimulation of the latter via the arm route could not be achieved in most of the cases in which it was possible via the femoral route. The inability to stimulate the His bundle in most of the cases via the arm approach is probably caused by the lack of precise pinpoint positioning of the tip electrodes.

\section{References}

Castellanos, A., Chapunoff, E., Castillo, C., Maytin, O., and Lemberg, L. (1970). His bundle electrograms in two cases of Wolff-Parkinson-White (pre-excitation) syndrome. Circulation, 41, 399.

Gallagher, J. J., Damato, A. N., Lau, S. H., Tower, A. J., Caracta, A. R., Varghese, P. J., and Josephson, M. E. (1973). Antecubital vein approach for recording His bundle activity in man. American Heart fournal, 85, 199.
Giraud, G., Puech, P., Latour, H., and Hertault, J. (1960). Variations de potentiel lieés à l'activité du système de conduction auriculoventriculaire chez l'homme (enrégistrement électrocardiographique endocavitaire). Archives des Maladies du Coeur et des Vaisseaux, 53, 757.

James, T. N. (1970). The Wolff-Parkinson White syndrome: evolving concepts of its pathogenesis. Progress in Cardiovascular Diseases, 13, 159.

Narula, O. S. (1973a). Conduction disorders in the A-V transmission system. In Cardiac Arhhythmias: 25th Hahnemann Symposium, p. 259. Ed. by L. S. Dreifus and W. Likoff. Grune and Stratton, New York.

Narula, O. S. (1973b). Wolff-Parkinson-White syndrome (a review). Circulation, 47, 872.

Narula, O. S. (1973C). Advances in clinical electrophysiology: contribution of His bundle recordings. In Cardiac Pacing. p. 33I. Ed. by P. Samet. Grune and Stratton, New York.

Narula, O. S., Cohen, L. S., Samet, P., Lister, J. W., Scherlag, B., and Hildner, F. J. (1970a). Localization of A-V conduction defects in man by recording of the His bundle electrogram. American Heart fournal of Cardiology, 25, 228.

Narula, O. S., Lister, J. W., Cohen, L. S., and Samet, P. (1968). Localization of A-V conduction delays in man. Circulation, 38, Suppl. VI, 146.

Narula, O. S., and Samet, P. (197I). Right bundle branch block with normal, left or right axis deviation: analysis by His bundle recordings. American fournal of Medicine, 51, 432.

Narula, O. S., and Samet, P. (1972). Recording of His bundle electrograms via the arm veins (abstract). Circulation, 46, Suppl. II, I97.

Narula, O. S., Scherlag, B. J., and Samet, P. (1970b). Pervenous pacing of the specialized conducting system in man. His bundle and A-V nodal stimulation. Circulation, 4r, 77.

Narula, O. S., Scherlag, B. J., Samet, P., and Javier, R. P. (1971). Atrioventricular block: localization and classification by $\mathrm{His}$ bundle recordings. American fournal of Medicine, 50, 146.

Rosen, K. M., Loeb, H. S., Chuquimia, R., Sinno, M. Z., Rahimtoola, S. H., and Gunnar, R. M. (1970). Site of heart block in acute myocardial infarction. Circulation, 42, 925.

Rosen, K. M., Rahimitoola, S. H., Chuquimia, R., Loeb, H. S., and Gunnar, R. M. (197I). Electrophysiological significance of first degree atrioventricular block with intraventricular conduction disturbance. Circulation, 43, 491.

Scherlag, B. J., Lau, S. H., Helfant, R. H., Berkowitz, W. D., Stein, E., and Damato, A. N. (1969). Catheter technique for recording His bundle activity in man. Circulation, 39, 13.

Watson, H., Emslie-Smith, D., and Lowe, K. G. (1967). The intracardiac electrocardiogram of human atrioventricular conducting tissue. American Heart fournal, 74, 66.

Requests for reprints to Dr. Onkar S. Narula, Division of Cardiology, Mount Sinai Medical Center, 4300 Alton Road, Miami Beach, Florida 33140, U.S.A. 